\title{
OCCIPITO-CERVICAL FUSION
}

\author{
Indications, Technique and Results \\ D. L. Hamblen, London, England \\ From the London Hospital
}

Fusion of the occiput to the upper cervical spine is an uncommon but important operation as it is the only means of permanently stabilising the intervening joints. Instability of the atlas or axis on the remainder of the cervical spine is dangerous, and if it progresses to subluxation or dislocation there is a risk of damage to the medulla, spinal cord and nerve roots. Fusion may be required for primary conditions causing instability in this region, such as congenital anomalies, spontaneous atlanto-axial dislocation, or post-traumatic dislocation following fracture of the dens [odontoid process]. It may also be necessary as a means of restoring stability after extensive cervical decompression by laminectomy.

Occipito-cervical fusion was reported by Foerster (1927), who used a fibular graft to stabilise a progressive atlanto-axial dislocation after fracture of the dens. Juvara and Dimitriu (1928) attempted to fuse an unstable atlanto-axial dislocation with a tibial graft in a patient with tetraplegia: this patient died. The first reported operation using an iliac bone graft was that of Kahn and Yglesias (1935) in a case of progressive atlanto-axial subluxation after failed conservative treatment for a fracture of the dens. They stressed the advantages of iliac bone which was easily moulded to the area of fusion.

Rand (1944) employed the operation for spontaneous atlanto-axial subluxation, and subsequently there have been many reports of its use in these conditions, resulting from loosening of the attachments of the transverse ligament of the atlas from acute or chronic inflammation. It has also been used for atlanto-axial instability in association with various developmental bony anomalies in the region of the foramen magnum. Spillane, Pallis and Jones (1957) reviewed twenty-four such patients, six of whom underwent the operation with improvement. The most recent indication has been its use in total cervical spine fusion in severe muscle paralysis from poliomyelitis as reported by Perry and Nickel (1959). The only previously reported series of any size is that of Lipscomb (1957), who reported nine cases, five for congenital anomalies and four for post-traumatic instability.

\section{CLINICAL MATERIAL}

In the past fifteen years thirteen patients have undergone occipito-cervical fusion at the London Hospital for a wide range of indications. Five were men and eight were women, and their ages at the time of operation varied from five to sixty-three years. The indication for operation in twelve of the cases was gross instability of the atlanto-axial region, complicated in nine instances by neurological symptoms and signs. In the other case the operation was performed prophylactically in a patient with marked progressive collapse of the upper cervical spine from rheumatoid arthritis. The causes of instability and the clinical details are shown in Table I. Six patients had multiple congenital anomalies, resulting in basilar impression in three and subluxation in the remainder. One patient had a separate dens as an isolated congenital anomaly. Infection with spontaneous atlanto-axial subluxation occurred in one case, and there was progressive collapse of the cervical spine from extensive rheumatoid arthritis in the other five.

Congenital anomalies other than separate dens-There were six patients in this group, and in three (Cases 3 to 5 ) progressive neurological involvement from instability was the presenting

VOL. 49 B, NO. 1, FEBRUARY 1967 
symptom. In two others (Cases 1 and 2) the condition was symptomless until a traumatic incident caused a transient neurological disturbance. In the remaining case (Case 6) the presenting symptoms were prolonged progressive pain and stiffness in the neck of a man with widespread neurofibromatosis.

\section{CASE REPORTS}

Case 1-A girl of five fell out of a sink in September 1959, landing heavily on her back and injuring her head and neck. She was not unconscious, but immediately developed right hemiplegia. Radiographs revealed a fissured fracture in the parietal region of the skull, and what appeared to be a fracturedislocation of the second cervical vertebra on the third, with separation of the bodies from the neural arches (Fig. 1). Further films showed widening of the cervical canal and congenital abnormalities of the third and fourth vertebral bodies which were not joined to their neural arches, so that the nature of the underlying condition became apparent. Myelography was normal, with no block in the widened cervical canal. The child's mother had noticed that her neck was rather short and limited in its movement.

Treatment by skull traction led to neurological improvement, and after four weeks a plaster collar was applied. This was worn for three months, after which there was only slight residual weakness of the right arm and leg, with increased tendon reflexes and unsustained right ankle clonus. Operation was performed in January 1960 . The radiological abnormalities were confirmed and the loose laminae were removed from the third and fourth vertebrae. The foramen magnum was decompressed posteriorly, where it had assimilated the missing arch of the atlas. Fusion was effected by twin iliac grafts extending

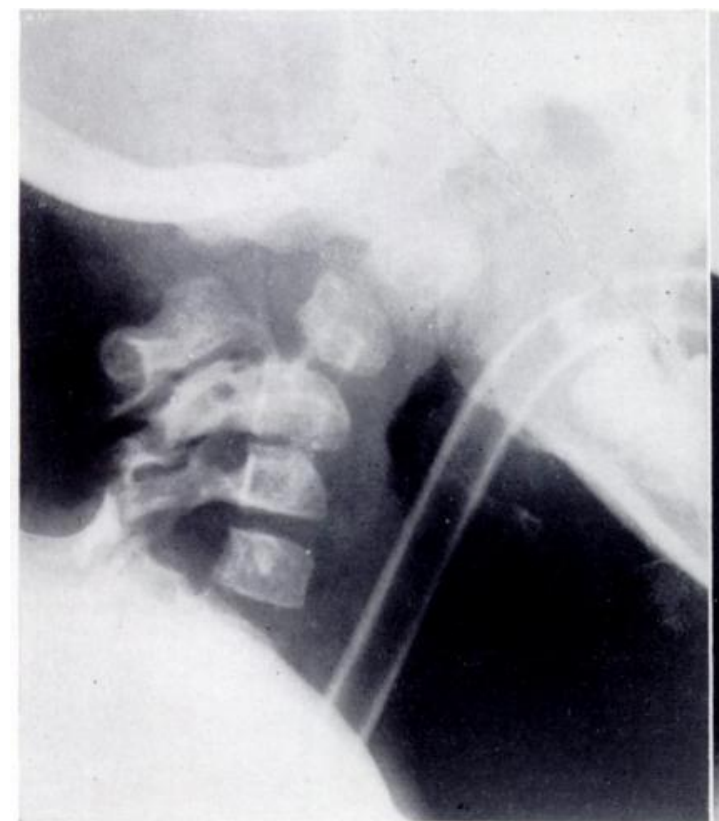

FIG. 1

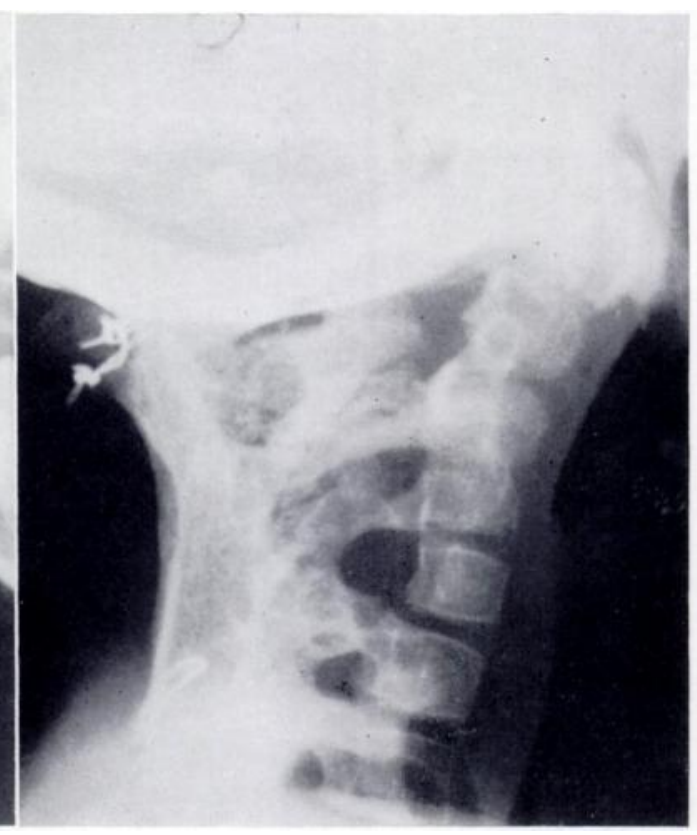

Fig. 2

Case 1. Figure 1-Lateral radiograph showing congenital anomalies of the upper cervical spine. Figure 2Lateral radiograph six months later showing occipito-cervical fusion.

from the occiput to the spinous processes of the fifth and sixth cervical vertebrae. Immobilisation in a plaster bed for three months was followed by application of a Minerva plaster for a further three months. Radiographs then showed fusion (Fig. 2). The right leg was noticed to be still a little spastic, but the girl was able to lead a normal active life.

Case 2-A man of twenty-one related that five years before he had developed transient paralysis of all four limbs, lasting several hours, following a rugby tackle. He was referred in June 1961 because of the onset of persistent clicking and pain in the neck on flexion, with recurrent transient weakness in the limbs. The only abnormal neurological signs were slight wasting and increase in tone of the muscles of the left arm. Radiographs of the cervical spine (Fig. 3) revealed a congenital malformation of the atlas, with absence of the lateral parts of the posterior arch and slight forward slip of the anterior arch. 
In July 1961 occipito-cervical fusion was performed, an iliac graft being wired to the occiput and the spinous process of the axis. Fusion was sound after two months in a plaster bed and three months in a Minerva jacket (Fig. 4).

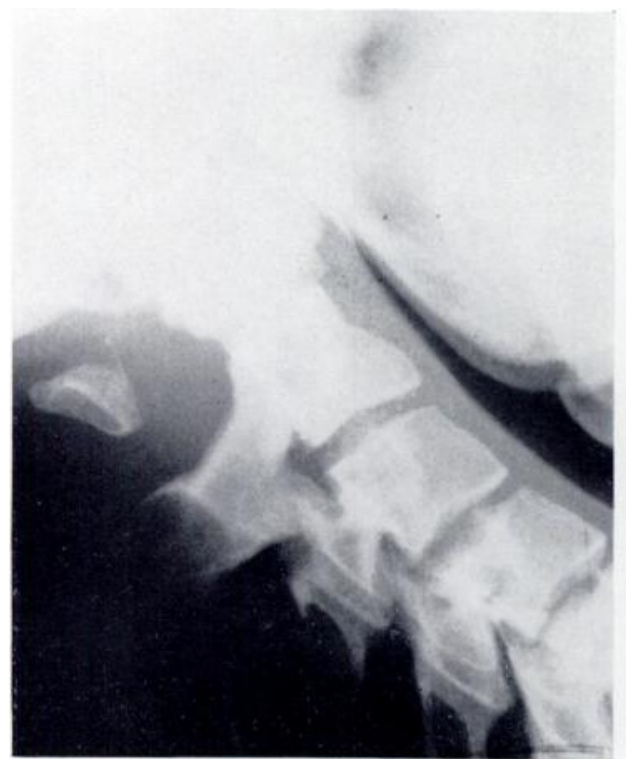

FIG. 3

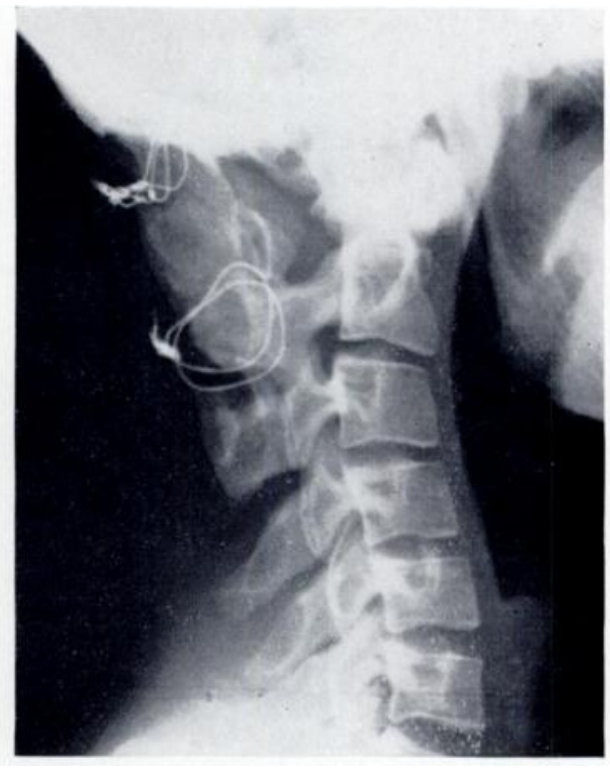

Fig. 4

Case 2. Figure 3-Lateral radiograph showing congenital malformation of the arch of the atlas. Figure 4-Lateral radiograph five months after occipito-cervical fusion.

Case 3-A woman of thirty-two was referred in February 1957 with a history of twenty years' increasing weakness in the legs, with almost complete paralysis of the right arm and leg for the last two years. In addition she had occasional dysphagia, constipation and frequency of micturition. Treatment with skull traction for several months had resulted in no improvement. Examination revealed a stunted, underdeveloped trunk with severe scoliosis and a typical platybasia deformity of the skull and neck. There was spastic weakness of the right upper and lower limbs with flexion deformities of the wrists, fingers and foot. In addition, posture and vibration sense was impaired in her right hand. A radiograph showed an advanced degree of basilar impression with the foramen magnum and arch of the atlas invaginated into the posterior fossa of the skull. In flexion the dens was lying close to the anterior lip of the foramen magnum in a most alarming position.

Operation was performed in two stages, with ten days interval between them. The foramen magnum was decompressed by the removal of two centimetres of bone from the lip in the midline posteriorly, and the tight dura mater was incised. At the second stage a single iliac graft was inserted and fixed to the occiput above and the laminae of the third and fifth vertebrae below. Fusion was evident after three months and the spastic paralysis of the right arm and leg slowly improved, though recovery was not complete.

Case 4-A boy of fifteen was referred in March 1959, with increasing difficulty in swallowing, regurgitation of fluids and an increasing left hemiparesis for three months. He was known to have a cleft palate, facial asymmetry and scoliosis. A radiograph revealed fusion of the dens with the foramen magnum and inversion of the posterior edge of the foramen causing basilar impression. Operation was undertaken in two stages. First the posterior fossa was decompressed, and three weeks later fusion was performed. The loose lamina of the axis had been removed and the split iliac grafts were wired from the occipital burr holes to the laminae of the third, fourth and fifth vertebrae. Fusion was evident after five months and his neurological state returned to normal.

Case 5-In October 1962 a man of fifty was referred from another hospital with increasing weakness of his legs and stumbling gait; he also complained of double vision, tingling in both arms and legs, and urinary incontinence, the earlier diagnosis being disseminated sclerosis. On examination he had a short neck and mild spastic paresis of both upper and lower limbs. A radiograph of the cervical spine showed the atlas to be fused to the base of the skull, and a separate dens allowing the skull and atlas to dislocate forwards on the axis. Operation was carried out in two stages with an interval of 
seven weeks between them. First decompression of the foramen magnum was performed with removal of the bone posteriorly for $1 \frac{1}{2}$ centimetres and incision of the thickened dura mater. At the second operation a single iliac bone graft was applied to the upper spine and fixed by sutures to burr holes in the occiput and to the laminae of the third and fourth vertebrae. Fusion was evident radiologically after five months but there was little improvement in his clinical condition.

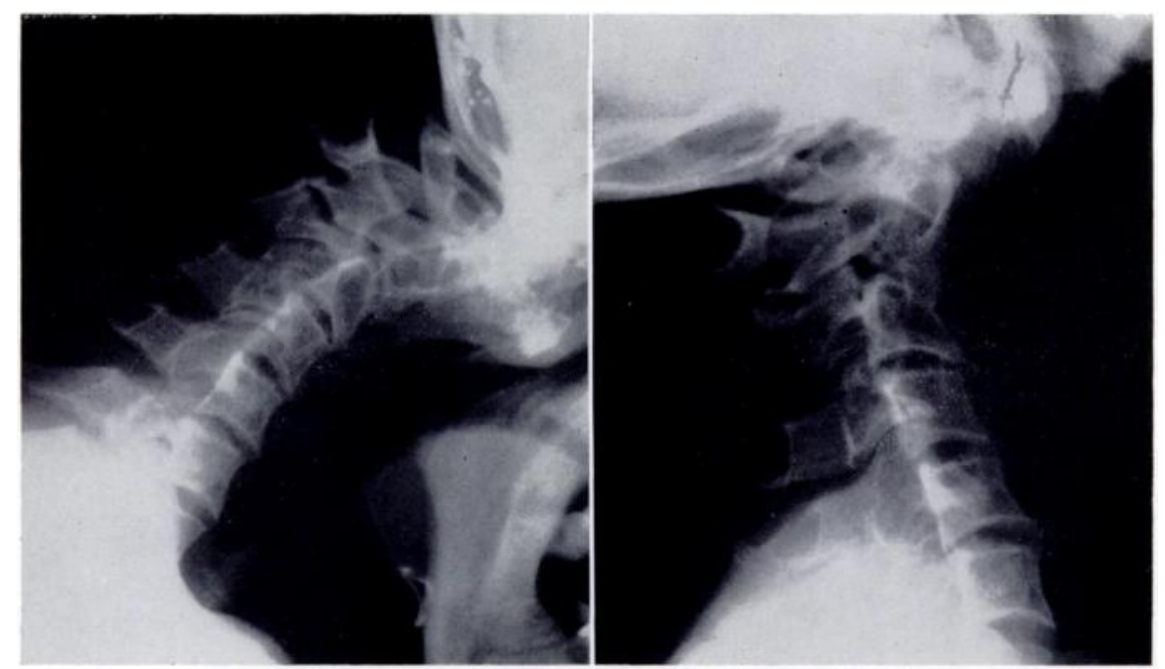

FIG. 5

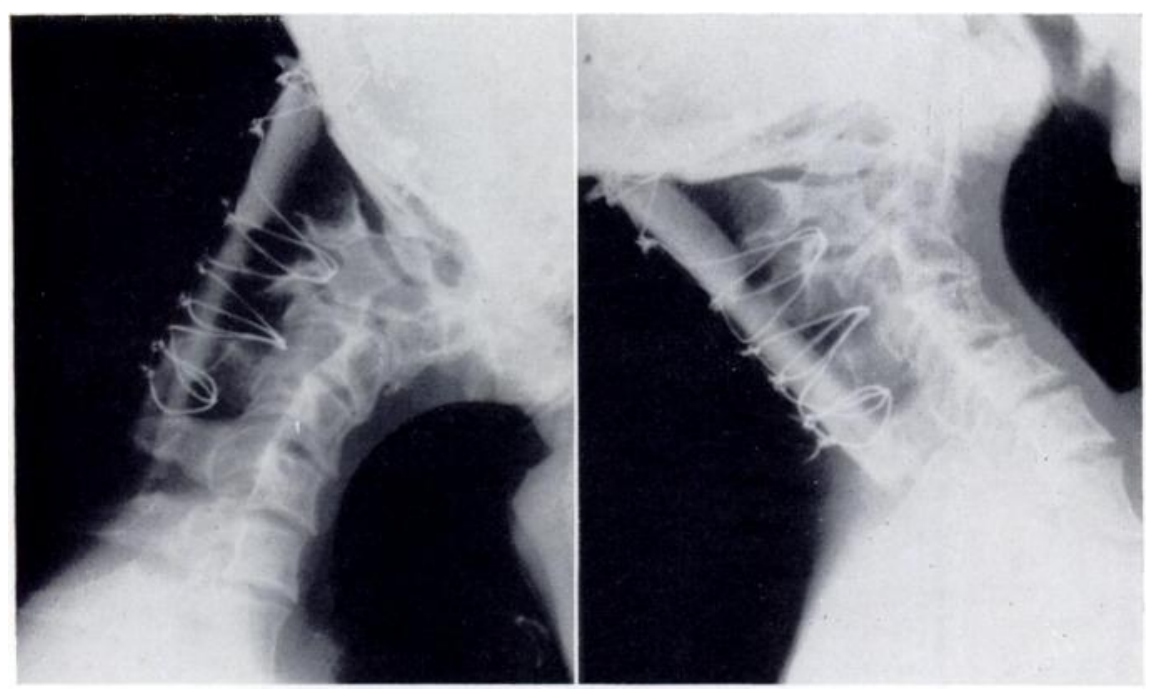

Fig. 6

Case 6. Figure 5-Lateral radiographs in flexion and extension to show instability due to skeletal neurofibromatosis. Figure 6-Lateral radiographs three months later in flexion and extension after occipito-cervical fusion using tibial grafts.

Case 6-A man of forty had had extensive neurofibromatosis and skin pigmentation since childhood. For ten years he had experienced increasingly severe attacks of stiffness and pain in the neck which had become continuous. Despite treatment with skull traction and a plaster collar this persisted, although he showed no neurological signs. A radiograph of the cervical spine (Fig. 5) showed disorganisation of the first and second cervical vertebrae with collapse and forward displacement of the atlas. At operation twin tibial grafts were fixed above to occipital burr holes and below to the laminae of the fifth and sixth cervical vertebrae. A radiograph after three months showed fusion (Fig. 6) and he became symptomless after discarding his collar. 
Separate dens--This developmental anomaly was well reviewed by Wollin (1963). He clearly defined the tomographic features which distinguish this condition from fracture of the dens. These are a small corticated ossicle, separated from the base of the dens by a plane of cleavage above the level of the superior articular processes of the axis (Fig. 7). In addition there are often associated bony abnormalities of an underdeveloped anterior arch of the atlas and an attenuated, often bifid, posterior arch.

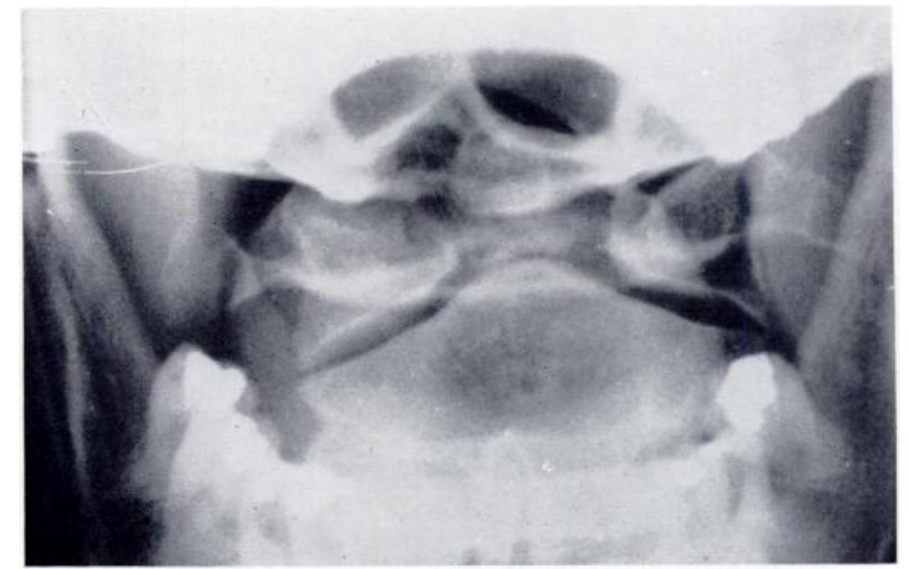

FIG. 7

Case 7-Antero-posterior radiograph showing the separate dens.

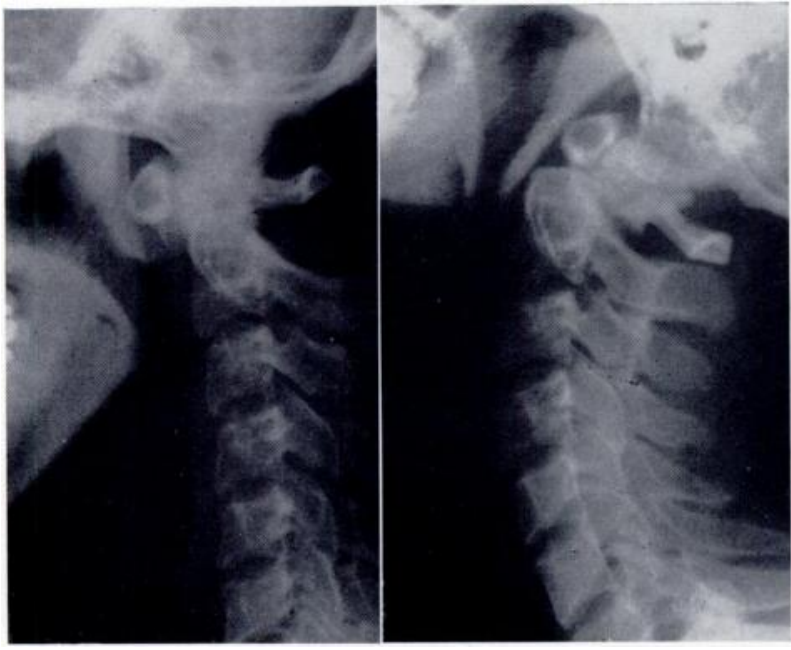

FIG. 8

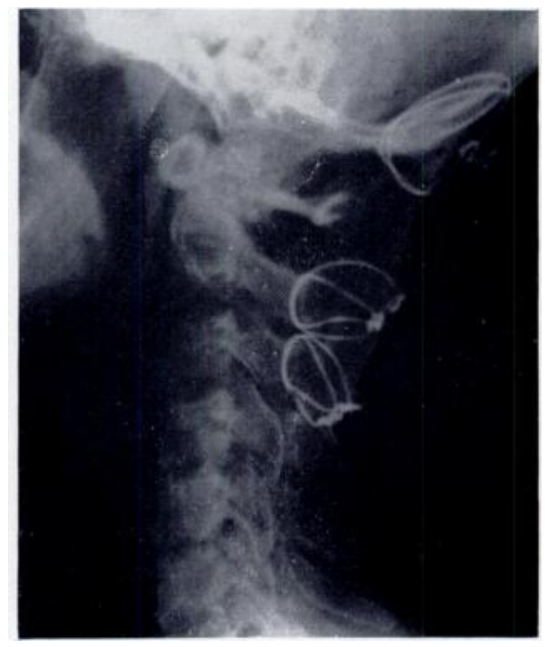

FIG. 9

Case 7. Figure 8-Lateral radiographs in flexion and extension showing the atlanto-axial instability due to a separate dens. Figure 9-Lateral radiograph three months after occipito-cervical fusion.

One case occurred in this series which was symptomless, but the patient was referred after a routine radiograph in a neurological department, where she had attended for investigation of quite unrelated symptoms. This radiograph (Fig. 8) showed the typical congenital anomaly with marked instability.

Case 7-A woman of twenty-eight had noticed tingling and slight weakness in her right hand one year before, associated with slight wasting but no alteration in muscle tone. Operation was performed in January 1964 and two iliac grafts were wired in place from occipital burr holes to the laminae of the second and fourth vertebrae. Fusion was solid after three months (Fig. 9) and she had no complaints about her neck, although the symptoms in her right hand were unchanged. A stress fracture of the graft occurred after eighteen months.

VOL. 49 B, NO. 1, FEBRUARY 1967 
Spontaneous atlanto-axial dislocation-This condition has been widely reported since the first classical case of Bell (1830), described after necropsy in a case of syphilitic pharyngeal ulcer. It is a recognised complication of many inflammatory processes, both acute and chronic, and the pathology was first described by Watson-Jones (1932): it consists in hyperaemia and decalcification of the atlas with consequent loosening of the attachments of its transverse ligament. It is more dangerous than either a separate or fractured dens, as this bony process remains intact and does not slide forward with the subluxating atlas, so compressing the brain stem. Watson-Jones emphasised the good results of conservative treatment with rest and support in cases following acute inflammation. This may not always be the case: instability may persist as in Case 8, and is probably permanent in cases of chronic inflammation as shown in Cases 9 to 12. In these patients with widespread rheumatoid arthritis causing joint collapse and destruction, often exacerbated by steroid therapy, fusion must be undertaken early to prevent severe spinal cord involvement.

Case 8-A man of forty-five had five years previously developed meningitis following a large boil on his neck. He was unconscious for several days but responded to antibiotic therapy and was able to

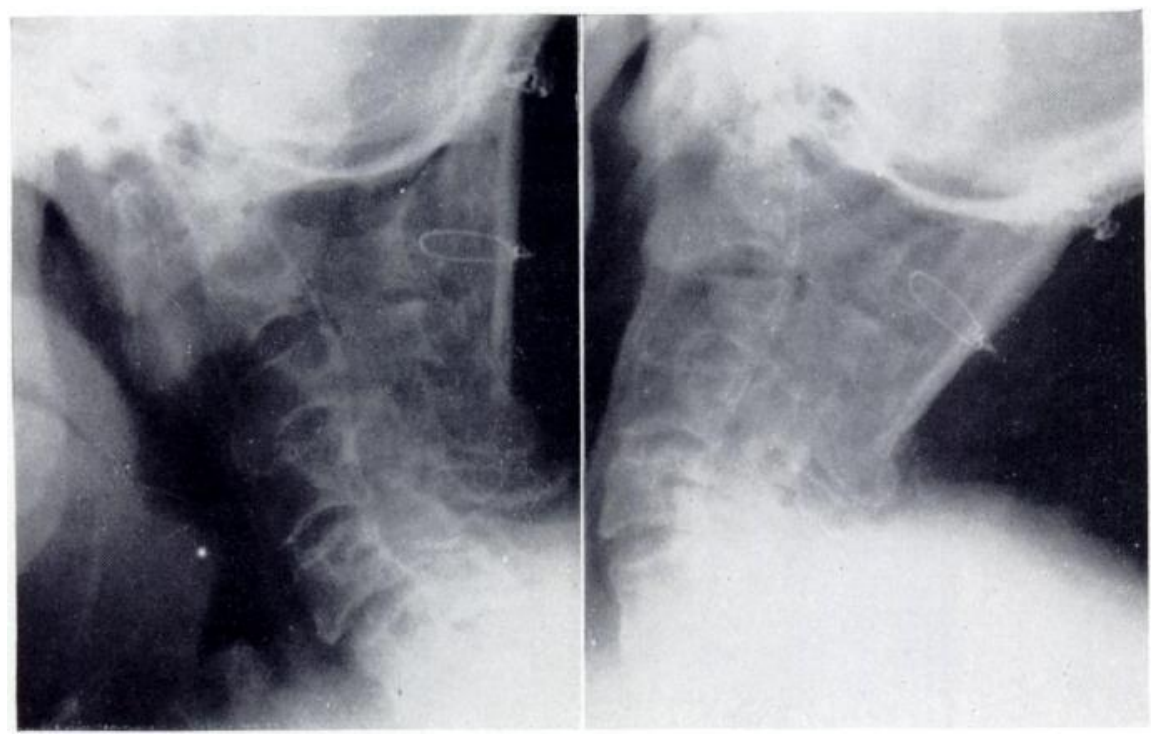

Fig. 10

Case 8-Lateral radiographs in flexion and extension five months after occipito-cervical fusion.

return to work one year later with only slight neck stiffness. He remained well until a year before admission when he was struck on the back of the neck by a crane hook. Following this incident he developed increasing pain in the neck, bifrontal headaches, projectile vomiting, and for the last month weakness and numbness in his hands and legs. On examination at this time he was found to have a soft tender swelling in his neck from the occiput to the fifth cervical vertebra, with diminished movement, especially flexion and extension. Neurologically he showed weakness and wasting of both hands, and slight increase in all tendon reflexes. A radiograph of the cervical spine showed a tilt of the axis on the third cervical vertebra, with forward dislocation of the atlas, and compression of the contents of the foramen magnum by the dens and the posterior arch of the atlas. In February 1950 operation was performed to decompress the suboccipital region and fuse the occiput to the cervical spine. The compressing arch of the atlas was removed and the thickened dura mater incised before the posterior margin of the foramen magnum was enlarged. A single tibial graft was wired in place from the occipital burr holes down to the spine of the axis. Skull traction was continued on a plaster bed for eight weeks, but the post-operative course was uneventful and radiographs in flexion and extension (Fig. 10) after five months showed sound union and no subluxation.

Of the four cases of rheumatoid arthritis showing subluxation, all had been on longterm steroid therapy, which may have contributed to the development of instability. 
Case 9-A woman of forty-two had developed generalised rheumatoid arthritis twelve years before. Four years before admission she had begun steroid therapy and after two years had undergone arthrodesis of one knee. From this time she had increasing pain in her neck and occipital region, with radiation to both shoulders. For the last year she had noticed " crunching " sensations in the upper neck with associated transient vertigo on rotation. She also had deafness, paraesthesia and numbness on one side of the face with associated cranial nerve signs, although she had no neurological signs in the limbs. She could demonstrate a terrifying subluxation of her own head which she could move forwards and backwards with her hands. A radiograph revealed a grossly abnormal atlantooccipital area, with a small dens showing excessive movement in relation to the arch of the atlas on flexion and extension. Operation was performed in March 1964 and the joint stabilised with a single iliac graft fixed to occipital burr holes above and the laminae of the second and fourth vertebrae below. A radiograph after six months when she discarded her collar showed sound fusion and the neurological symptoms had gone.

Case 10-A woman of fifty-three had had widespread rheumatoid arthritis for twenty-eight years with increasing pain and joint deformities. Seven years before admission she had had splenectomy for splenomegaly and anaemia, and at this time she was started on steroid therapy. After a hyperflexion injury to her neck two and a half years before she began to complain of persistent paraesthesia over the right side of the occiput. A radiograph at this time showed collapse and derangement of the upper cervical spine and she was given a supporting collar. Despite this her symptoms persisted with the onset of paraesthesia in her right arm, leg and side of the face. For the last year she had experienced clonic spasm at intervals in the right leg and was also complaining of occasional urinary incontinence. Examination on admission showed generalised weakness and wasting of all muscles, and definite spasticity with extensor spasm in both legs. A radiograph of the cervical spine showed a widened gap between the dens and the arch of the atlas due to subluxation, and a myelograph confirmed compression at this level. Pre-operative treatment with skull traction improved the neurological state and in October 1963 occipito-cervical fusion was performed. A single iliac graft was inserted and fixed to occipital burr holes and the lamina of the fourth cervical vertebra, as well as the posterior arch of the atlas. Initially the muscle spasms in her legs became worse, requiring intensive antispasmodic treatment, but later they slowly improved and she was able to walk with the aid of crutches after six months. A radiograph of the neck at this time showed the graft in a satisfactory position and soundly incorporated.

Case 11-A woman of fifty-eight had suffered from widespread rheumatoid arthritis from the age of nineteen. Six years before she had begun steroid therapy and later had an operation for arthrodesis of the left ankle. In the course of four months she gradually developed profound tetraparesis, more marked on the right side, with inability to stand or walk. A radiograph showed forward subluxation of the atlas on the axis, and an incomplete fusion from the third to the fifth cervical vertebrae. Skull traction was applied with marked improvement in the neurological state after only three hours. This was continued for six weeks until operation in June 1963. A single iliac graft was fixed from the occiput above to the lamina of the fourth cervical vertebra below. After four months a radiograph showed sound fusion, and she was just able to stand, although still mainly confined to a wheelchair.

Case 12-A woman of forty-nine had had widespread rheumatoid arthritis for ten years for which she had been given steroid therapy for six years. Her main complaint for the last five years was severe occipital headaches radiating to the frontal region, and also blurred vision. A radiograph showed forward shift of the atlas on the axis with backward dislocation of the dens. Operation was performed in February 1965: the atlas was found to be partly fused to the occiput, with an unstable axis. A single iliac graft was fixed from the occiput to the lamina of the third cervical vertebra with a central wire looped around the arches of the atlas and axis. After four months' immobilisation she was free of symptoms and a radiograph showed fusion.

Case 13-A woman of sixty-three had had rheumatoid arthritis for eight years. Five years before admission she underwent subtotal thyroidectomy for toxic goitre, and after this she noticed increasing neck stiffness and pain radiating to the occiput and to both shoulders. This increased despite neck traction, manipulation and wearing a cervical collar. She had no abnormal neurological signs. A radiograph of the cervical spine showed widespread rheumatoid involvement of the joints including the atlanto-occipital articulation, and a flexion film revealed slight subluxation of the axis on the third cervical vertebra. A myelograph showed slight compression at two levels and it was decided to do a prophylactic fusion. In December 1959 occipito-cervical fusion was done with a single iliac graft, wired to the occiput and the spines of the axis and sixth cervical vertebra. After six months a radiograph showed fusion, but she still complained of pain in the neck, though not as severe as before.

VOL. 49 B, NO. 1, FEBRUARY 1967 
Traumatic dislocations and fractures of the atlas or axis-Other writers have advised that fracture of the dens is an indication for operation, but no patients underwent occipito-cervical fusion for instability as a result of trauma in this series. Rogers (1957) reported an end-result study of nine cases of fracture of the dens with non-union in four cases, two of which were undisplaced. Two of these patients underwent occipito-cervical fusion, and the other two had local fusion of atlas to axis. In ununited fracture of the dens with an intact neural arch of the atlas it is sufficient to fuse the atlas to the vertebrae below. However, as Forsyth, Alexander, Davis and Underdal (1959) stressed (see Discussion), the fusion should be carried down to include the third cervical vertebra, and not to the axis alone as was done in the following case.

Case 14-A man of twenty sustained a whiplash injury while a back seat passenger in a car involved in a collision. He had a head injury and on recovering consciousness complained of pain in his neck and difficulty in flexing and extending it. A radiograph revealed a fracture through the base of the dens and his neck was immobilised in a plaster collar. After seven months further radiographs showed an ununited fracture of the dens with undue atlanto-axial mobility. Fusion was undertaken. A double iliac bone graft was wired in place from the posterior arch of the atlas to the spine of the axis. After four months radiological fusion was present. This patient's spine might have dislocated although there was no displacement at the time of operation.

TABLE I

SUMmary OF OCCIPITO-CERVICAL Fusions

\begin{tabular}{|c|c|c|c|c|}
\hline $\begin{array}{c}\text { Case } \\
\text { number }\end{array}$ & Sex & $\underset{(\text { years })}{\text { Age }}$ & Indication for operation & Neurological involvement \\
\hline 1 & Female & 5 & $\begin{array}{l}\text { Congenital anomalies of } \\
\text { upper cervical vertebrae }\end{array}$ & Right hemiplegia \\
\hline 2 & Male & 21 & $\begin{array}{c}\text { Congenital malformation of } \\
\text { arch of atlas }\end{array}$ & Transient tetraplegia \\
\hline 3 & Female & 32 & $\begin{array}{l}\text { Congenital anomalies, } \\
\text { platybasia and basilar compression }\end{array}$ & Spastic right hemiplegia \\
\hline 4 & Male & 15 & $\begin{array}{l}\text { Congenital anomalies, } \\
\text { platybasia and basilar compression }\end{array}$ & Left hemiparesis \\
\hline 5 & Male & 50 & $\begin{array}{l}\text { Congenital anomalies of } \\
\text { upper cervical spine }\end{array}$ & $\begin{array}{l}\text { Spastic paresis } \\
\text { both upper and lower limbs }\end{array}$ \\
\hline 6 & Male & 40 & $\begin{array}{l}\text { Skeletal neurofibromatosis with } \\
\text { vertebral anomalies }\end{array}$ & None \\
\hline 7 & Female & 28 & Separate dens & $\begin{array}{l}\text { None. } \\
\text { Unrelated weakness right hand }\end{array}$ \\
\hline 8 & Male & 45 & $\begin{array}{c}\text { Spontaneous atlanto-axial dislocation } \\
\text { after sepsis }\end{array}$ & Weakness and wasting both hands \\
\hline 9 & Female & 42 & $\begin{array}{l}\text { Spontaneous atlanto-axial dislocation. } \\
\text { Rheumatoid arthritis and steroids }\end{array}$ & Cranial nerve irritation \\
\hline 10 & Female & 53 & $\begin{array}{l}\text { Spontaneous atlanto-axial dislocation. } \\
\text { Rheumatoid arthritis and steroids }\end{array}$ & Spastic paraparesis \\
\hline 11 & Female & 58 & $\begin{array}{l}\text { Spontaneous atlanto-axial dislocation. } \\
\text { Rheumatoid arthritis and steroids }\end{array}$ & Paraparesis \\
\hline 12 & Female & 49 & $\begin{array}{l}\text { Spontaneous atlanto-axial dislocation. } \\
\text { Rheumatoid arthritis and steroids }\end{array}$ & None \\
\hline 13 & Female & 63 & $\begin{array}{l}\text { Disorganisation of cervical spine. } \\
\text { Rheumatoid arthritis }\end{array}$ & None \\
\hline
\end{tabular}




\section{OPERATION}

The technique of the operation is based on that described by Cone and Turner (1937) and elaborated by Robinson and Southwick (1960) with some modifications. It was developed at the London Hospital by $\mathrm{Mr} \mathrm{H}$. Osmond-Clarke and $\mathrm{Mr} \mathrm{D}$. W. C. Northfield and it is recommended that whenever possible it should be carried out as a joint orthopaedic and neurosurgical procedure.

The operation may be performed in two stages with an interval between suboccipital decompression and fusion. This staging is advisable if the patient's condition is not fit for the whole operation at one time. In one of our cases an interval of seven weeks was used. It is also advisahle to noctnone fucion if there hac heen a leak of cerehrocninal fluid into the 
D. L. HAMBLEN 
After operation the patient is placed in a plaster bed, and when excessive instability has been present before operation skull traction of about ten pounds weight is continued for two weeks. After three months the patient is fitted with a Minerva plaster and after another four to six weeks a moulded leather or polythene collar is worn for a further three to six months. If a tibial graft is used it is wise to apply a walking plaster to the leg to prevent stress fracture, which occurred in one of our cases.

\section{RESULTS}

At follow-up nine patients were interviewed and the remainder had clinical records and radiographs sufficiently detailed for valid conclusions. The longest follow-up was fifteen years and the shortest four months.

No death occurred at operation or in the immediate period after operation. One patient (Case 13) died five years after operation from coronary thrombosis.

The view that it is difficult to obtain fusion at the base of the skull was not found to be justified in this series, for no case failed to fuse in six months. The average period of immobilisation after operation was seven months, of which three were in a plaster bed, and the remaining four in a plaster jacket or collar. One important late complication in two patients (Cases 1 and 7) was fracture of the graft. In Case 1 the graft fractured at its upper end after four years; this was due to rapid growth in the anterior part of the child's spine outpacing the fixed graft. It caused no symptoms other than slight clicking in the neck and the fusion was sound enough; further surgical intervention was not indicated. In Case 7 the patient had noticed clicking in her neck after only eighteen months and a radiograph showed a stress fracture at the junction of the upper and middle thirds of the graft. This, too, was stable and did not require further operation. The patient in Case 6 developed a stress fracture of the left tibia eighteen months after removal of the graft. After six months in plaster union occurred.

Complete relief of symptoms was obtained in eight of the thirteen cases and was particularly gratifying in four of the eight with neurological involvement. Improvement over the pre-operative state was obtained in another four patients including three of those with neurological involvement. In only one case did deterioration continue after operation. This was Case 5, in which there was undoubtedly disseminated sclerosis in addition to the congenital vertebral anomalies. This resulted in a steady deterioration in his general condition, although no symptoms or signs were referable to his cervical spine.

After operation the average range of movement was 10 to 20 degrees of flexion and extension, 10 degrees of lateral flexion and 10 to 20 degrees of rotation. Initially this limitation of movement was a nuisance to the patients but as new habits of turning the whole body were learnt it became less of a burden.

\section{DISCUSSION}

From the results of operation in this and other series the indications for operation can be laid down. Simple instability between the first and second cervical vertebrae, such as may occur with fractures of the dens, does not require fusion of the occiput to the upper vertebral spine providing the posterior arch of the atlas is intact. It is sufficient to fuse the atlas to the vertebral arches below, although as Forsyth et al. (1959) pointed out, fusion should include both the second and third cervical vertebrae: when they fused the atlas to the axis alone redislocation occurred in two out of fourteen. If the fracture involves the arch of the atlas extensively, or laminectomy is required to decompress the brain stem, then the fusion must extend up to include the occiput. As an alternative it is possible to perform interbody fusion between the atlas and axis using the approach through the back of the mouth described by Southwick and Robinson (1957). Congenital anomalies are common in the region of the foramen magnum and often result in basilar impression and neurological symptoms. If decompression is required 
it must be followed by occipito-cervical fusion, often as a later second stage operation. In addition, widespread replacement of normal bone by neurofibromata may cause softening and displacement needing fusion. The anomaly of a separate dens, however, does not require a full occipito-cervical fusion, and in retrospect our case could have been adequately treated by fusion of the atlas to the second and third cervical vertebrae. This would have prevented the stress fracture of the graft.

Spontaneous atlanto-axial dislocations as a result of acute infections in the nose, throat or ear often respond to conservative treatment as suggested by Watson-Jones (1932). A few cases may show persistent laxity, and careful observation is required to recognise these cases and prevent any disastrous sudden dislocation with gross neurological damage. If, after an adequate trial of conservative treatment for six months there is still radiological evidence of instability, fusion must be undertaken. Increasing incidence of atlanto-axial instability is now being recognised in chronic inflammatory diseases. Sharp and Purser (1961) reported a series of forty-eight patients, the underlying pathology being ankylosing spondylitis in twenty-two and rheumatoid arthritis in twenty-six. From a study of the general population in Britain they suggest an incidence of instability of thirty-two per thousand in subjects with any evidence of rheumatoid arthritis, of sixty-four per thousand in patients with clinical evidence of the disease, and of 189 per thousand admitted to hospital with this condition. They stress three clinical features suggestive of early instability: persistent pain in the upper neck with occipital radiation, difficulty in extending the neck and tendency for the head to fall into flexion, and flattening of the normal occipito-cervical curve. When instability occurs with neurological signs, it should be treated by early fusion, as it is unlikely to respond to conservative treatment, and prolonged steroid therapy will contribute to the softening and slow healing. Those cases without evidence of nerve or spinal cord involvement may be given a trial of conservative treatment with supporting casts and collars.

Total neck fusion including the occiput has already been described by Perry and Nickel (1959) for severe muscular paralysis following poliomyelitis.

\section{SUMMARY}

1. Thirteen cases of occipito-cervical fusion performed in the past fifteen years at the London Hospital are described.

2. Seven of the patients had congenital anomalies in the region of the foramen magnum, six had spontaneous atlanto-axial dislocations, and in one case the operation was performed prophylactically to stabilise a severely disorganised cervical spine.

3. Nine of the patients had evidence of neurological involvement before operation due to pressure on the spinal cord or nerve roots.

4. Operative fusion was successful in all cases and there was no operative mortality.

5. The clinical results were good in eight cases and four patients were improved. The condition of one patient, in whom progressive disseminated sclerosis was also present, deteriorated.

6. The technique of operation is described, and it is recommended that it should always be performed as a combined orthopaedic and neurosurgical procedure.

My grateful thanks are due to Mr H. Osmond-Clarke, Mr W. A. Law, Mr D. W. C. Northfield and Mr J. V. Crawford for allowing me to review these patients who were under their care. I also wish to thank Mr R. F. Ruddick and his staff for the photographs, and Miss Anne Cooper for valuable secretarial assistance.

\section{REFERENCES}

BeLl, C. (1830): The Nervous System of the Human Body. Appendix CXXVII, No. LXIV. London: Longman, Rees, Orme, Brown and Green.

Cone, W., and Turner, W. G. (1937): The Treatment of Fracture-Dislocations of the Cervical Vertebrae by Skeletal Traction and Fusion. Journal of Bone and Joint Surgery, 19, 584.

Foerster, O. (1927): Die Leitungsbahnen des Schmerzgefühls, p. 266. Berlin und Wein: Urban \& Schwarzenburg. 
Forsyth, H. F., Alexander, E., Jun., Davis, C., Jun., and Underdal, R. (1959): The Advantages of Early Spine Fusion in the Treatment of Fracture-Dislocation of the Cervical Spine. Journal of Bone and Joint Surgery, 41-A, 17.

Juvara, E., and DimitriU, V. (1928): Luxation atloïdo-axoïdienne avec phénomènes compressifs, Opération secondaire. Lyon Chirurgical, 25, 668.

Kahn, E. A., and Yglesias, L. (1935): Progressive Atlanto-Axial Dislocation. Journal of the American Medical Association, 105, 348.

Lipscomb, P. R. (1957): Cervico-Occipital Fusion for Congenital and Post-Traumatic Anomalies of the Atlas and Axis. Journal of Bone and Joint Surgery, 39-A, 1289.

Perry, J., and Nickel, V. L. (1959): Total Cervical-Spine Fusion for Neck Paralysis. Journal of Bone and Joint Surgery, 41-A, 37.

Rand, C. W. (1944): The Neurosurgical Patient. Springfield, Illinois: Charles C. Thomas.

Robinson, R. A., and Southwick, W. O. (1960): Surgical Approaches to the Cervical Spine. Instructional Course Lectures of the American Academy of Orthopaedic Surgeons, 17, 299.

Rogers, W. A. (1957): Fractures and Dislocations of the Cervical Spine. An End-Result Study. Journal of Bone and Joint Surgery, 39-A, 341.

Sharp, J., and Purser, D. W. (1961): Spontaneous Atlanto-Axial Dislocation in Ankylosing Spondylitis and Rheumatoid Arthritis. Annals of the Rheumatic Diseases, 20, 47.

Southwick, W. O., and Robinson, R. A. (1957): Surgical Approaches to the Vertebral Bodies in the Cervical and Lumbar Regions. Journal of Bone and Joint Surgery, 39-A, 631.

Spillane, J. D., Pallis, C., and Jones, A. M. (1957): Developmental Abnormalities in the Region of the Foramen Magnum. Brain, 80, 11.

Watson-Jones, R. (1932): Spontaneous Hyperaemic Dislocation of the Atlas. Proceedings of the Royal Society of Medicine (Section of Orthopaedics), 25, 586.

Wollin, D. G. (1963): The Os Odontoideum. Separate Odontoid Process. Journal of Bone and Joint Surgery, 45-A, 1459. 